\title{
Sagittal Maxillary Fracture: Diagnosis and Management
}

\author{
Umesh Kumar ${ }^{1}$ Pradeep Jain ${ }^{1}$ \\ ${ }^{1}$ Department Plastic Surgery, Institute of Medical Sciences, Banaras \\ Hindu University, Varanasi, Uttar Pradesh, India
}

Address for correspondence Umesh Kumar, MCh (Plastic Surgery, 25 Brij Enclave Extension-1, PO-Bazardiha, Varanasi 221 109, UP, India (e-mail: umeshkrplastic@gmail.com).

Indian J Plast Surg 2021;54:284-288.

\begin{abstract}
Keywords

- sagittal maxillary

fracture

- palatal vault fracture

- anterior alveolar plating

- palatal vault plating

- maxillary buttress stabilization

Background The sagittal maxillary fracture often coexists with maxillary fractures and warrants a definitive management strategy together with other maxillary fractures. Method This study was conducted on 60 patients suffering from sagittal maxillary fracture. Palatal fractures were classified into six subgroups. During management, patients were divided into three groups. In group A, patients with type I, IV, V, and VI were managed with maxillomandibular fixation and anterior maxillary buttress stabilization. Group B patients included type II, III, and IV palatal fractures. These fractures were undisplaced and were managed with maxillomandibular fixation, anterior alveolar plating, and anterior maxillary buttress stabilization. Group C included type II and III fractures with visible gap in the palate and were managed with maxillomandibular fixation, palatal vault plating, anterior alveolar plating, and anterior maxillary buttress stabilization.

Result Sagittal maxillary fracture was more common in young males. Le Fort I and II fractures were more frequently associated with it in isolation or in combination. Parasagittal and sagittal fractures were the most common types. Sixteen patients of group A, twenty patients of group B, and twenty-four patients of group $C$ were managed. Malocclusion (2), plate extrusion (2), and oroantral fistula (2) were the most common complications.

Conclusion Sagittal maxillary fracture can be diagnosed with clinical and radiological examination. Palatal vault plating is required in displaced palatal fractures of type II and III. Single plate fixed in posterior half of middle one-third of palate gives sufficient stability to the palatal vault.
\end{abstract}

\section{Introduction}

Maxillary fracture is a common clinical condition presenting in triage of trauma center. The ratio of mandible fracture to maxillary fracture is $4: 1{ }^{1}$ Le Fort classified maxillary fractures in three categories. ${ }^{2}$ However, in clinical practice majority of Le Fort fractures present in different combinations and may vary in presentation on either side. ${ }^{3}$ Fracture of maxilla may also occur in sagittal plane resulting in splitting of palate in longitudinal manner at the junction of the maxilla with vomer. ${ }^{4}$ Making diagnosis, classifying and formulating a definitive management of Le Fort fractures with palatal fracture are a challenging task for a plastic surgeon. In palatal fracture patient, restoration of transverse width, maintaining published online August 2, 2021
DOI https://doi.org/

$10.1055 / \mathrm{s}-0041-1729665$ ISSN 0970-0358
(C) 2021. Association of Plastic Surgeons of India

This is an open access article published by Thieme under the terms of the Creative Commons Attribution-NonDerivative-NonCommercial-License, permitting copying and reproduction so long as the original work is given appropriate credit. Contents may not be used for commercial purposes, or adapted, remixed, transformed or built upon. (https://creativecommons.org/licenses/by-nc-nd/4.0/).

Thieme Medical and Scientific Publishers Pvt. Ltd. A-12, 2nd Floor, Sector 2, Noida-201301 UP, India 
vertical height and anterior projection of midface with achieving normal occlusion, is the primary objective of management. ${ }^{5}$ In our study, we detected palatal fracture in patients presenting with maxillary fractures, divided them into three categories and managed them accordingly.

\section{Materials and Methods}

This study was conducted in Department of Plastic Surgery from 2016 to 2020 in 60 patients presenting with sagittal maxillary fracture. Each patient was initially evaluated at triage area to rule out airway, neurosurgical, surgical, and orthopaedic emergencies. Patients with facial fractures were evaluated for clinical symptom and signs of malocclusion, open bite, widening of midface, anterior upper alveolar fracture, lacerations over face, and palatal mucosa or ecchymosis of palatal mucosa in closed fracture. In all patients, computed tomography (CT) scan was performed with sections in the axial as well as coronal plain with special emphasis for three-dimensional reconstruction and visualization of palatal bones. Classification of maxilla fractures was done as per Le Fort classification and palate fractures were subcategorized as by Hendrickson et al comprehensive CT-based classification, which describes palate fracture in 6 subheadings ${ }^{6}(-$ Fig. 1 ). Management of palate fracture was done after thorough investigation, under nasal or submental intubation and was categorized into three subgroups. In group A subgroup, there was radiological evidence of fracture without displacement and the fracture was of type I, type IV, type V, or type VI that was managed by application of interdental wiring, Erich arch bar application, and anterior maxillary buttress stabilization after open reduction and internal fixation with mini plates and screws. If any patient required additional splintage, he was referred to a dental outpatient department (-Table 1). In group B subgroup of patients that comprised of type I, type II, type III, and type IV palate fractures was managed with Erich arch bar, anterior alveolar plating, infiltration of palatal mucosa with $1 \%$ lignocaine with adrenaline, dissection of mucoperiosteal flaps and suturing if required, followed by anterior maxillary buttress stabilization. Maxillomandibular fixation was continued for 4 to 6 weeks depending on the stability achieved ( - Supplementary Table 1; available online only). In group C subgroup patients with type II and type III fractures, there was widening in palatal vault width with visible gap. These subsets of patients were managed by applying Erich arch bar, infiltration of palatal mucosa with $1 \%$ lignocaine with adrenaline $(1: 100000)$, followed by reduction in fracture with Hayton Martins forceps, mobilization of mucoperiosteal flaps $\sim 1 \mathrm{~cm}$ on both sides and fixing the fracture in posterior half of middle one-third of hard palate with $2 \mathrm{~mm}$ three-hole plate with gap after molding it to the shape of arch of the palate with $4 \mathrm{~mm}$ long and $2 \mathrm{~mm}$ diameter screws. After palatal vault plating, the implant was covered with healthy mucoperiosteal flaps. Anterior alveolar and anterior maxillary buttress stabilization with plates and screws was also done followed by maxillomandibular fixation for 4 to 6 weeks ( - Supplementary Table 2; available online only). Thus, type IV fractures were managed in groups A and B depending on fracture displacement present at anterior alveolar region. Type II and III fractures were managed in group B and C depending on displacement present in palatal vault. Oral hygiene was maintained with repeated use of mouth wash and the patients were kept on liquid diet for 6 weeks. They were followed at 4, 6, 8, and 12 weeks for observation of occlusion and the arch bar was removed between 6 and 8 weeks.
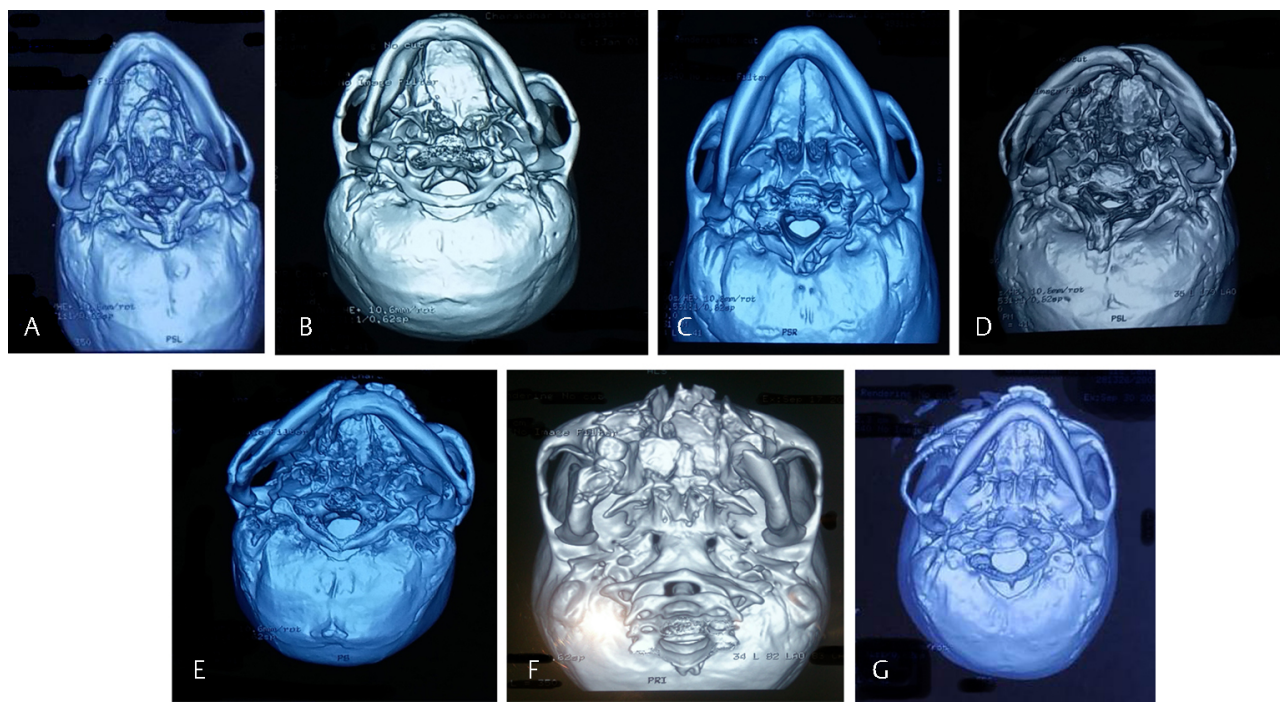

Fig. 1 Three-dimensional computed tomography scan images of Hendrickson's classification. (A) Type I alveolar (anterior). (B) Type I alveolar (posterolateral). (C) Type II sagittal fracture with gap. (D) Type III parasagittal fracture with bone loss. (E) Type IV paraalveolar fracture. (F) Type V complex fracture. (G) Type VI transverse fracture. 
Table 1 Patients divided into three groups for management, type of palatal fracture in each group, mode of injury, treatment and complication

\begin{tabular}{|c|c|c|c|c|}
\hline $\begin{array}{l}\text { Group } \\
\text { (No. of patients) }\end{array}$ & $\begin{array}{l}\text { Type of palatal fracture (No. } \\
\text { of patients) }\end{array}$ & $\begin{array}{l}\text { Mode of injury } \\
\text { (No. of patients) }\end{array}$ & Treatment & $\begin{array}{l}\text { Complication (No. of } \\
\text { patients) }\end{array}$ \\
\hline Group A (n-16) & $\begin{array}{l}\text { 1. Alveolar (Type I)(n-7) } \\
\text { a) Anterior (1) } \\
\text { b) Posterolateral (6) } \\
\text { 2. Para alveolar (Type IV)(n-5) } \\
\text { 3. Complex (Type V) (n-1) } \\
\text { 4. Transverse (Type VI) (n-3) }\end{array}$ & $\begin{array}{l}\text { 1. Assault }-7 \\
\text { 2. RTA }-5 \\
\text { 3. Sports injury }-1 \\
\text { 4. Fall from height }-2 \\
\text { 5. Battery blast - } 1\end{array}$ & $\begin{array}{l}\text { MMF with anterior maxillary } \\
\text { buttress stabilization }\end{array}$ & $\begin{array}{l}\text { 1. Malocclusion }-1 \text {. } \\
\text { 2. Ectrotion lower eyelid } \\
-1\end{array}$ \\
\hline Group B (n-20) & $\begin{array}{l}\text { 1. Sagittal (Type II)(n-5) } \\
\text { 2. Para sagittal (Type III)(n-7) } \\
\text { 3. Para alveolar (Type IV)(n-8) }\end{array}$ & $\begin{array}{l}\text { 1. RTA - } 16 \\
\text { 2. Fall from height }-3 \\
\text { 3. Assault - } 1\end{array}$ & $\begin{array}{l}\text { MMF with anterior alveolar } \\
\text { plating and anterior maxil- } \\
\text { lary buttress stabilization }\end{array}$ & $\begin{array}{l}\text { 1. Fistula }-1 \\
\text { 2. Malocclusion }-1 \text {. }\end{array}$ \\
\hline Group C (n-24) & $\begin{array}{l}\text { 1. Sagittal (Type II)(n-11) } \\
\text { 2. Para sagittal (Type III)(n-13) }\end{array}$ & $\begin{array}{l}\text { 1. RTA }-17 \\
\text { 2. Fall from height }-2 \\
\text { 3. Assault }-3 \\
\text { 4. Sports injury }-2\end{array}$ & $\begin{array}{l}\text { MMF with palatal vault plat- } \\
\text { ing anterior alveolar plating } \\
\text { and anterior maxillary } \\
\text { buttress stabilization }\end{array}$ & $\begin{array}{l}\text { 1. Plate exposure }-2 \\
\text { 2. Fistula }-1\end{array}$ \\
\hline
\end{tabular}

Abbreviation: RTA - Road Traffic Accident, MMF - Maxillo Mandibular Fixation.

\section{Result}

Sixty patients with sagittal maxillary fractures, that is palatal fractures, were diagnosed from 436 maxillary fractures. Age of our patients varied from 4 to 60 years. Male to female ratio was $56: 4(14: 1)$. As per history, 38 patient sustained injury due to road traffic accident, 11 suffered injury due to assault, 7 sustained injury due to fall from height, 3 had sports injury, and 1 patient suffered fracture due to mobile battery blast. Palatal fractures were classified according to Hendrickson's classification: 16 patients had sagittal fracture, 20 had parasagittal fracture, 7 patients presented with alveolar fracture ( 1 anterior and 6 posterolateral), 13 patients had paraalveolar fracture, 1 patient had complex fracture, and 3 patients presented with transverse fracture. Fractures associated with palatal fracture were Le Fort I in 15 (14 unilateral and 1 bilateral), Le Fort II in 15 ( 6 unilateral and 9 bilateral), combined Le Fort I and II (13 unilateral and 10 bilateral), combined Le Fort I, II, and III in 4, Le Fort II and III in 1, nasoethmoid fracture in 37, frontal bone fracture in 12, zygoma fracture in 29 , and mandible fracture in 37 patients, respectively.

Sixteen patients of group A were managed with maxillomandibular fixation and stabilization of anterior maxillary buttress. Twenty patients of group B were managed with maxillomandibular fixation, palatal suturing when required, anterior alveolar or pyriform plating, and anterior maxillary buttress stabilization. Twenty-four patients of group $C$ were managed with Erich arch bar application, palatal vault plating, anterior alveolar or pyriform plating, and anterior maxillary buttress stabilization. In follow-up, two patients presented with plate extrusion that was associated with loosening of screws and were managed by removing the plate. Two patients presented with palatal fistula in follow-up period (4-6 weeks). In one patient, there was loss of bone near the posterior nasal spine with loss of soft tissue. The fistula healed in due course of time after fistula closure surgery. Two patients complained of malocclusion that was managed with prolonged maxillomandibular fixation and dental consultation. One patient developed ectropion of lower eye lid that was managed after 6 months with full-thickness skin grafting.

\section{Discussion}

Sagittal maxillary fractures form a small percentage of Le Fort fractures. The incidence of palatal fractures coexisting with Le Fort fracture has been reported between 8 and $13.2 \%{ }^{7}$ Chen et al accounted that $46.4 \%$ of their patients with maxillary fracture also had palatal fracture and that they almost never occurred in isolation. ${ }^{8}$ Hendrickson et al classified palatal fractures based on location and anatomical characteristics of injury. They divided palatal fractures in (a) alveolar (type I) that can be of two subtypes-anterior and posterolateral, (b) sagittal (type II), (c) parasagittal (type III), (d) paraalveolar (type IV), (e) complex (type V), and (f) transverse (type VI). ${ }^{6}$ On the other hand, Park and Ock classified palatal fractures based on closed reduction, site of fixation, stability of fractured segment after rigid fixation and categorized their patients into four subgroups: (a) closed reduction (CR type), (b) rigid fixation of maxillary buttress and alveolar ridge (anterior or A type), (c) rigid fixation of palatal vault and anterior structures (AP type), and (d) rigid fixation with extended immobilization(combined or C type). ${ }^{9}$ However, Chen et al described a simplified classification combining anatomical characteristics and optimal treatment. The categories were sagittal (type I), transverse (type II), and comminuted (type III) fractures.

In our case series of 60 patients, parasagittal (20) and sagittal (16) fracture were the most common palatal fracture types. Sagittal fracture is more common in younger patients in the first three decades of life but can occur in older patients depending on the intensity of trauma. Melsen in his study described that palatal sutures ossify between the second and third decade. ${ }^{10}$ The young male population is active and prone to road traffic accidents. Besides, severe intensity of impact sustained in road traffic accidents, incomplete ossification or no ossification could also be an important 
contributory factor for causing sagittal and parasagittal fractures. Hoppe et al in their study also, like in our series, concluded that alveolar and parasagittal fractures were the most frequent type of palatal fracture and the main cause of fracture was assault followed by motor vehicle accidents. ${ }^{11}$ While describing parasagittal and paraalveolar fractures, one may find difficulty in categorizing fractures that are oblique or are in lazy S pattern, because such fracture may be parasagittal in the anterior part and paraalveolar in the posterior part of hard palate. So, such fracture trajectory would not fit in any category described so far. We had such fracture lines in eight patients out of sixty. Park and Ock in his study suggested median and paramedian nomenclature as words sagittal and parasagittal imply direction only rather than specific location of fracture. ${ }^{9}$

In our series, associated fractures with sagittal maxillary fractures were Le Fort I in 15 (14 unilateral and 1 bilateral), Le Fort II in 15 (unilateral and 9 bilateral), and Le Fort I and II combined in 23 (13 unilateral and 10 bilateral). The mandible fracture was also associated with 37 patients. The most common fracture in different series was orbit fracture, ${ }^{11}$ Le Fort I (100\%), ${ }^{6}$ Le Fort II with mandible (61\%), ${ }^{9}$ and Le Fort II (66\%). ${ }^{12}$ Thus, palatal fractures can present with multiple fractures and the commonest one associated with it is Le Fort II and Le Fort I in isolation or in combination. It is important to note that during management of these fractures, the first fracture to be addressed is the palatal fracture if there is displacement or widening or visible gap in the palatal arch.

Palatal fractures have been managed by various techniques like K-wire fixation, interfragmentary wires, intermolar wiring, Erich arch bar with maxillomandibular fixation, transverse palatal wires, horizontal mattress wires, figure of eight wiring, and application of palatal acrylic splints. All these methods do help in management but do not achieve rigid immobilization in unstable fractures. Open reduction and internal fixation were first described by Quinn who combined rigid internal fixation of palatal vault with a palatal splint. ${ }^{13}$ Extensive plate and screw fixation of vertical maxillary and pyriform aperture are sufficient for stabilization of maxillary and palatal fracture. ${ }^{14,15}$ Manson et al were first to describe occlusal rigid internal fixation of the palatal vault. ${ }^{7}$ Hendrickson et al advocated open reduction and internal fixation for accurate and stable alignment of fracture by plating at two places in palatal vault, fracture through dental arch and anterior four vertical buttress of the maxilla.

Park and Ock divided their patients in four groups depending upon the treatment algorithm. The first group of palatal fracture was managed with closed reduction. In second group along with maxillary buttress stabilization, anterior alveolar ridge or pyriform rim plating was done. The third group was managed with palatal vault plating, anterior alveolar plating, and anterior maxillary buttress stabilization. In the fourth group, besides plating all the fractures as mentioned, immobilization was continued for 4 to 6 weeks to achieve better healing of fracture as in complex or transverse palatal fracture.

Palatal vault plating is necessary where there is visible or radiological defect in the palate. In most of our patients, there was an existing laceration in the palate, which may be taken as a tell tail sign and used for the elevation of mucoperiosteal flaps on both sides of the existing fracture line. Most of the surgeons have advocated plating at two sites in the palatal vault. Recently three-dimensional rectangular plates have been used to achieve greater stability of fracture segment. ${ }^{12}$ In our experience if there is an oblique, lazy $S$ type of fracture line and if the palate is high arch, then using a large rectangular frame plate may be technically difficult as the hole of plate may be quite close to the fracture line after contouring the plate. Cienfuegos et al used $2.0 \mathrm{~mm}$ locking plates and fixed them by placing over the palatal mucosa using the osteosynthesis as an external fixator. ${ }^{16}$ In our series, we used $2 \mathrm{~mm}$ three-hole plate with gap for fixation of the palatal vault fracture. Our observation is that once we reduce the fracture with Hayton Martins forceps and fix the fracture in the posterior half of middle one-third of palatal vault, we could achieve stable fixation with one screw on both sides of the fracture. It is much easier to contour the plate according to the curvature of palate and avoid fracture of edge during drilling holes for screws (-Fig. 2). This approach is advantageous as it avoids the territory of greater palatine vessel while elevating mucoperiosteal flaps and unnecessary dissection of palatal mucosa in the anterior one-third of palatal vault. Anterior alveolar or pyriform ridge plating helps in achieving complete stability of the fracture. Type II and III fractures were managed by this method.

Exposure of plate, oroantral fistula, and malocclusion is encountered in two cases each during follow-up. Exposed plate presented with loosening of screw and was removed
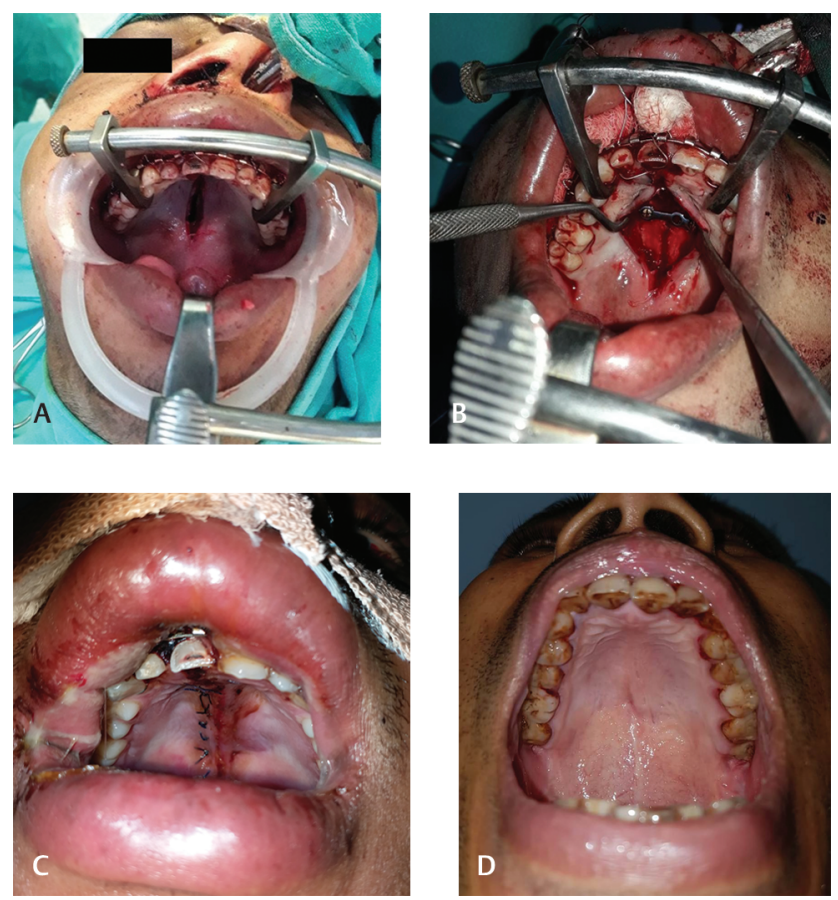

Fig. 2 (A) Sagittal maxillary fracture with visible gap. (B) Palatal vault plating in middle one-third of hard palate with three-hole plate with gap. (C) Plate covered with mucoperiosteal flaps and sutured in midline. (D) healed suture line. 
after signs of healing on X-ray under short general anesthesia. Manson et al documented hardware exposure in $10 \%$ of cases. ${ }^{5}$ Park and Ock mentioned of exposure of screw in one out of six patients. ${ }^{9}$ Chen et al have reported one case of infection and three cases of oroantral fistula in group of patients who had comminuted fracture. They have advocated for routine palatal flap for tension free closure in case where there is an obvious lack of bony support or bone loss. Out of 162 cases they achieved satisfactory occlusion in $85 \%$ of cases. ${ }^{8}$ In one case, there was bone loss at the posterior one-third of palate and wound dehiscence was observed on fourth postoperative day. After initial conservative approach, it was repaired later as for fistula closure.

\section{Conclusion}

Sagittal split maxillary fractures can be managed with or without palatal vault plating. Palatal vault plating should be done in fractures that present with displacement in posterior part of hard palate. Single plate is sufficient in achieving stability if an anterior alveolar plate is applied along with it.

\section{Note}

The study was approved by the Institutional review board. No clinical trial was performed during study.

\section{Source of Funding}

Nil.

\section{Conflict of Interest}

Nil.

\section{References}

1 Rowe NL, Killey HC, Fracture of the Facial Skeleton. 2nd edition. Baltimore: Williams \& Wilkins; 1968

2 Le Fort R. Experimental study of fractures of the upper jaw. Revue de Chirurgie(Paris) 1901;23:208-227
3 Manson PN. Some thoughts on the classification and treatment of Le Fort fractures. Ann Plast Surg 1986;17(5):356-363

4 Morgan BD, Madan DK, Bergerot JP. Fractures of the middle third of the face-a review of 300 cases. Br J Plast Surg 1972;25(2):147-151

5 Manson PN, Glassman D, Vanderkolk C, Petty P, Crawley WA. Rigid stabilization of sagittal fractures of the maxilla and palate. Plast Reconstr Surg 1990;85(5):711-717

6 Hendrickson M, Clark N, Manson PN, et al. Palatal fractures: classification, pattern and treatment with rigid internal fixation. Plast Reconstr Surg 1999;103:1287-1307

7 Manson PN, Clark N, Robertson B, et al. Subunit principles in midface fractures: the importance of sagittal buttresses, soft-tissue reductions, and sequencing treatment of segmental fractures. Plast Reconstr Surg 1999;103(4):1287-1306, quiz 1307

8 Chen $\mathrm{CH}$, Wang TY, Tsay PK, et al. A 162-case review of palatal fracture: management strategy from a 10-year experience. Plast Reconstr Surg 2008;121(6):2065-2073

9 Park S, Ock JJ. A new classification of palatal fracture and an algorithm to establish a treatment plan. Plast Reconstr Surg 2001;107(7):1669-1676, discussion 1677-1678

10 Melsen B. A histological study of the influence of sutural morphology and skeletal maturation on rapid palatal expansion in children. Trans Eur Orthod Soc 1972;•••:499-507

11 Hoppe IC, Halsey JN, Ciminello FS, Lee ES, Granick MS. A single centre review of palatal fractures: etiology, patterns, concomitant injuries and management. Eplasty 2017;17:e20

12 Karthik R, Cynthia S, Vivek N. Prashanthi G, Saravana Kumar $\mathrm{S}$, Rajyalakshmi V. Open reduction and internal fixation of palatal fractures using three-dimensional plates. $\mathrm{Br} \mathrm{J}$ Oral Maxillofac Surg 2018;56(5):411-415

13 Quinn JH. Open reduction and internal fixation of vertical maxillary fractures. J Oral Surg 1968;26(3):167-171

14 Rimmell F, Marentette LJ. Injuries of the hard palate and the horizontal buttress of mid face. Head Neck Surg 1993;109:499

15 Gruss JS, Mackinnon SE. Complex maxillary fractures: role of buttress reconstruction and immediate bone grafts. Plast Reconstr Surg 1986;78(1):9-22

16 Cientuegos R, Sierra E, Ortiz B, Fernandez G. Treatment of palatal fractures by osteosynthesis with $2.0 \mathrm{~mm}$ locking plates as external fixator. Cranio Maxilla Fac Trauma Reconstr 2010;3:223-230 